\title{
ALLOCATION OF POSTAL NETWORK FACILITIES, BASED ON EXISTING ROAD INFRASTRUCTURE
}

\author{
Jozef Štefunko ${ }^{1}$, Radovan Madleňák ${ }^{2}$
}

\begin{abstract}
Postal operator, as well as every network enterprise, needs to keep its costs on the lowest level possible, while maintaining the reliability and availability of its services. One option to the costs is to optimize the transport network. This article focuses on the creation of postal network based on existing road infrastructure in Slovakia. Except the basic analysis of the infrastructure, the research approach adopted in this article relies on methods of graph theory to solve allocation problems. In particular, it is the method of p-median values and its algorithms to determine the number and location of new postal sorting centers. The findings showed that the analysis performed is just the cornerstone in finding the optimal solution for such strategic investments. Results are bounded to the input values used, especially the distance of the network vertices. Specific values of postal sector need to be incorporated with more thorough analysis of road infrastructure, considering future development of transport network.
\end{abstract}

JEL Classification Numbers: L87, R53, DOI: http://dx.doi.org/10.12955/cbup.v3.586

Keywords: Postal network, infrastructure, allocation models, p-median

\section{Introduction}

Postal operation represents an extensive technological system with a considerable degree of integration for different types of services. The main business activity of postal operator is reliable, regular, and fast transport of postal items. The transport is performed among the stationary postal facilities with different levels of postal item processing (Čorejová, Achimský, Fitzová, \& Kajánek, 1995). Customer demands the delivery time to be minimal and guaranteed under the terms of the universal service and the nature of postal item, respectively. Moreover, the effort of postal operators as business entities is put forth, so that operations are carried out with minimal cost. Apart from the postal item processing technology, transport itself is an equally critical factor of time and cost. Transport is affected by the location of postal facilities and connections among them-the postal transport network.

\section{Suitable models for allocation of facilities in postal transport network}

The number and location of postal processing centers in the postal transport network is determined mainly by logistic functions of the entire postal system. The decision on where and how many top-level nodes to be located can be considered as strategic, and, therefore, it needs to be taken based on the results of the optimization process.

The graph theory is highly used in the optimization of transport networks. It enables us to describe and to abstract these networks and formulate different tasks to solve them (Černý \& Kluvánek, 1991). One of those tasks is finding the optimal location of facilities. Allocation models can be helpful in this case. The role of such mathematical models is to find answers to these key questions (Daskin, 2013):

- How many facilities need to be located?

- Where should each facility be located?

- How large should the facility be?

- What are the demands or how large is the area to be covered by an individual facility?

\footnotetext{
1 Jozef Štefunko, PhD Candidate, Faculty of Operation and Economics of Transport and Communications, University of Žilina, jozef.stefunko@fpedas.uniza.sk

2 Radovan Madleňák, PhD, Assoc. Prof., Faculty of Operation and Economics of Transport and Communications, University of Žilina, radovan.madlenak@fpedas.uniza.sk
} 
Allocation problems differ in the type of objective function and model of the environment in which they are addressed. Model of environment, in our case, is the transport network abstracted by the complete weighted graph $G=(V, E, c, w) . V$ is the set of nodes (vertices) representing possible facility locations. $H$ is the set of edges representing connections between nodes. Label $c(h)$ of edge $h \in H$ is its length. Weight $w(v)$ of node $v \in V$ represents the importance of the node in the addressed system (Janáček, 2006).

Postal transport network centers perform supplying function. To find the location, it is convenient to use discrete network allocation models. One of the basic parameters for solving problems of such type is the very distance between nodes. From this point of view, it is possible to subdivide allocation models into two categories (Madleňák, 2005):

Models based on maximum distance:

- set covering,

- maximum covering,

- p-center.

Models based on total or average distance:

- p-median,

- maximum,

- fixed charge facility location.

Models, based on the total, or covering distance seem to be the most appropriate for the issue addressed in this article. When locating facilities, these models do not take into account the maximum distance between the facility and demand node, but rather the total/average distance between the facilities and all demands. They ensure that the average distance between any vertex and facility location will be minimum possible. Thus, we decided to use the p-median allocation model.

\section{P-median allocation model}

The goal of this model is to find the location of $P$ facilities in the network, ensuring to serve all the demands and to minimize the average transport costs (Daskin, 2010). These costs can be determined by multiplying the demands of network node and the distance between a node and the closest facility serving its demands. P-median model works with the following variables (Daskin, 2013):

\section{Input variables:}

$I$ - set of nodes with demands to be served,

$J$ - set of candidate nodes for facility location,

$h_{i}$ - demand at node $i$,

$d_{i j}$ - distance between demand node $i$ and candidate node $j$,

$P$ - number of facilities to locate.

\section{Decision variables:}

$X_{j}$ - takes the value 1 , if we locate facility at candidate node $j$; takes the value 0 , if not

$Y_{i j}$ - takes the value 1 , if demands at node $i$ are served by facility at node $j$; takes the value 0 , if not The p-median problem can be formulated as follows:

To minimize:

$$
\sum_{i} \sum_{j} h_{i} d_{i j} Y_{i j}
$$


Subject to:

$$
\begin{gathered}
\sum_{j} Y_{i j}=1 \quad \forall i \in I \\
\sum_{j} X_{j}=P
\end{gathered}
$$

The objective function (1) minimizes the total demand-weighted distance between each demand node and the nearest facility. Constraint (2) requires each demand node $i$ to be assigned to exactly one facility $j$. Constraint (3) states that exactly $P$ facilities are to be located (Daskin, 2013).

The basic and simplest heuristic algorithm for solving the p-median allocation problem is myopic algorithm. It belongs to a group of construction algorithms, which involves finding an initial solution by successive selection of optimal locations for 1-median problem. The improvement algorithms are built upon construction algorithms. Their goal is to find the optimal or sub-optimal location for a facility. This group includes neighborhood search algorithm and exchange algorithm (Madleňák, 2005). Since the myopic algorithm finds the very first appropriate solution and does not try to optimize it, we use the neighborhood search algorithm (Figure 1).

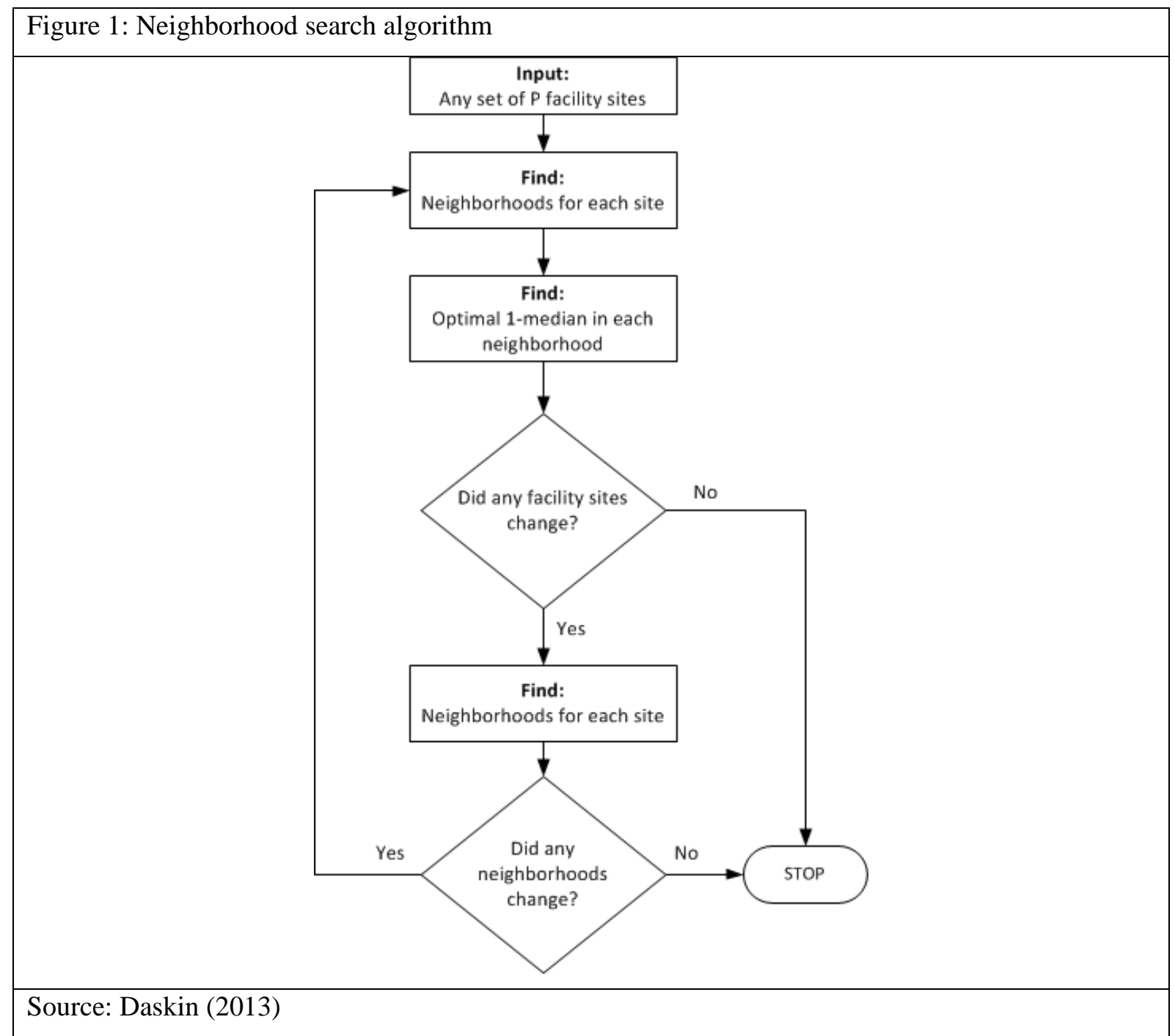

\section{Design of underlying network}

The knowledge of the environment is essential to designing and creating the postal network, especially its demographic and geographic parameters or administrative subdivisions. The most important in our case is the underlying infrastructure. The type of transport used in the postal sector depends entirely on 
the nature of postal items and transportation requirements. It is also influenced by the level of infrastructure development, potentially usable for postal item transportation in each country (Madleňák, Madleňáková, \& Štefunko, 2014). In Slovakia, it is the road transport that has the highest potential to be used in such case, for its high availability and flexibility.

We decided not to take into account the existing postal network, but we are dealing with the idea of creating a new network based on the existing transport infrastructure. The basic model of the environment is the complete weighted graph $G=(V, H, c, w)$.

The graph is built upon the basic territory administrative division of the Slovak Republic to the districts. We expect full availability for road transport. The Slovak Republic is divided into 79 districts. This number was reduced by merging city districts of Bratislava and Kosice, since they have one administrative center. Vertices are placed in the administrative centers of districts-district towns. The resulting number of vertices is 71 , which were placed on the blank map of Slovakia in order to maintain the similarity with their exact geographic location. The population of each district represents the number of demands to serve and, thus, determines the weight of the node.

The next step is to determine the set of edges and their weight for a graph representing road infrastructure. We used the route length measurement service on the Google Maps website. Each edge weight is based on the shortest metric distance between adjacent nodes. Links consisting of the lowest road class were not taken into account, as they are not suitable for the freight transport. We have not dealt with other quality parameters of links between two nodes, e.g. time required to cover the distance. The diagram of created graph is shown in Figure 2.

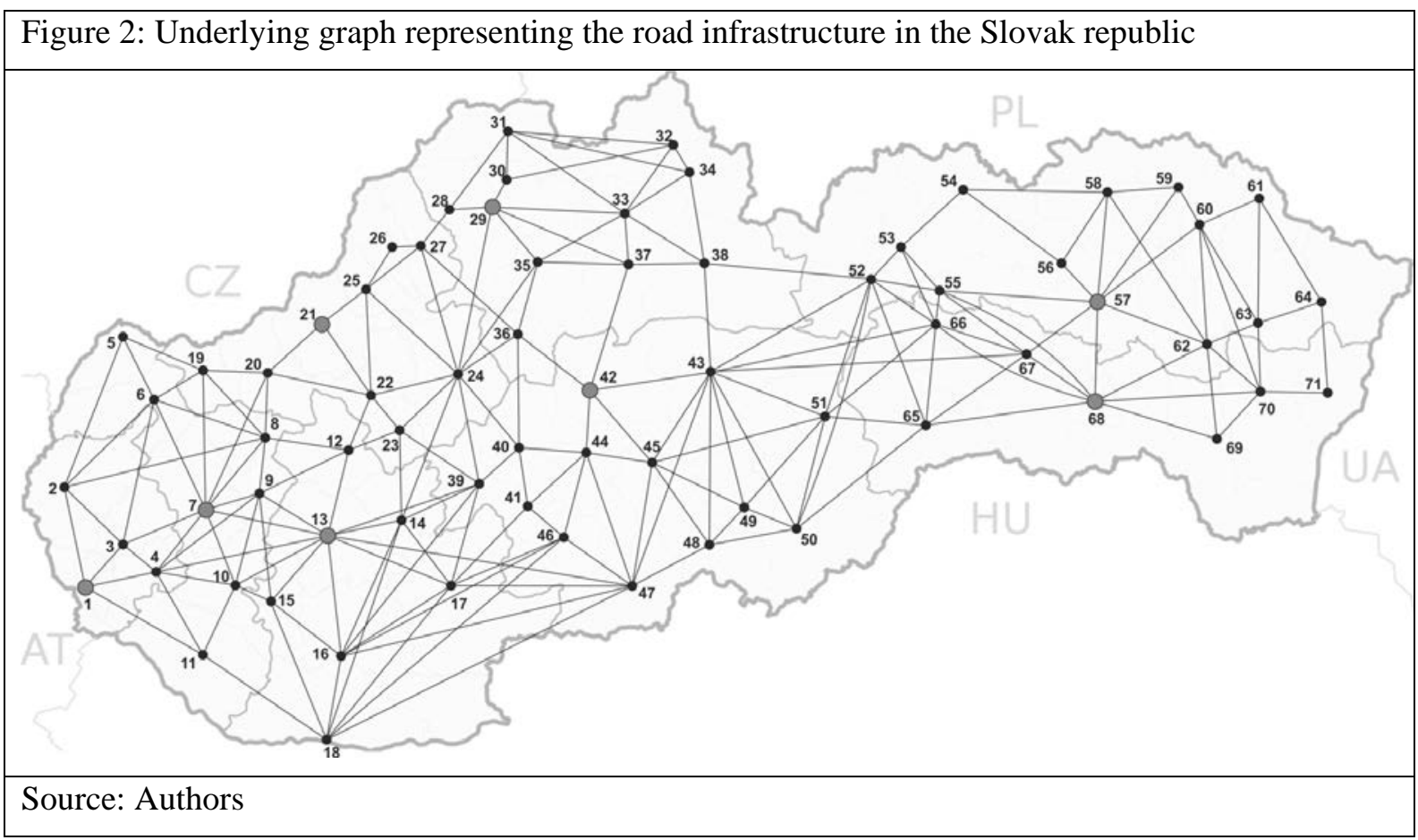

\section{Application of p-median allocation model on road infrastructure}

After analyzing and abstracting the existing infrastructure into a graph, it is necessary to determine the optimal location of the highest level postal processing centers. A random selection of large networks would be difficult and inaccurate; therefore, the allocation model is used to solve this issue. The previously mentioned p-median allocation model has been applied. Although there are known algorithms for optimal results in complex networks, they are time-consuming and complex computing solutions. To obtain results faster, we used the software created by Professor Mark S. Daskin called 
"SITATION." It is used to solve the allocation tasks using models based on the maximum and average distance.

In order to use p-median allocation model, other parameters need to be identified in addition to the underlying graph. What is important in designing the postal transport network is a variable describing the coverage of demand by the given node- the covering distance. Its value reflects the maximum distance required for the transport of postal items from the superior node (facility we want to locate) to subordinate node and vice versa. Due to the size of Slovakia and the results of the infrastructure analysis, we determined the covering distance of 60,90 , and $120 \mathrm{~km}$. The exact number of facilities is searched until all demands (all nodes) are covered. To obtain the solution, we use the aforementioned neighborhood search algorithm.

To avoid gradually adding more facilities and calculating the result of the solution to the p-median allocation problem for each variant (from one to the first optimal number of facilities), we can estimate the number of required facilities by the curve of covering distance, which is also called "p-median curve" (Figure 3). Estimation is confirmed, if the subsequent calculation succeeds in covering demands of all the nodes.

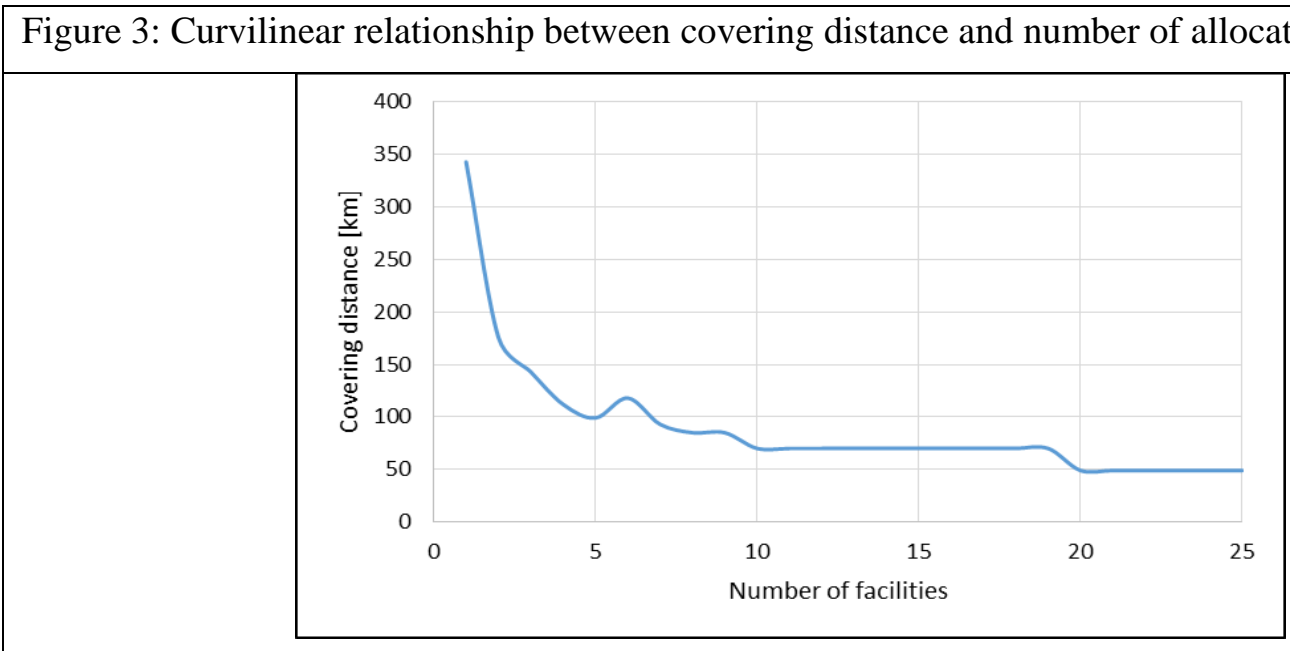

Source: Authors

P-median curve steeply descends for allocation of the first five facilities. When allocating ten or more facilities, the covering distance does not change for a long time until a jump to a lower value. An interesting point is the ascending of the curve when allocating six facilities. This is due to the fact that some node(s) are more distant from allocated facilities compared to the case of five or seven facilities. The overall location of the facilities is preferable for remaining network nodes (average distance between all the vertices is shorter).

Table 1: The obtained solution to the allocation problem for the chosen variants in covering distance

\begin{tabular}{|r|r|r|r|r|}
\hline $\begin{array}{c}\text { Covering } \\
\text { distance [km] }\end{array}$ & $\begin{array}{c}\text { Number of } \\
\text { facilities } \\
\text { [P] }\end{array}$ & \multicolumn{1}{|c|}{$\begin{array}{c}\text { Facility location } \\
\text { [Vertex number] }\end{array}$} & $\begin{array}{c}\text { Average } \\
\text { distance } \\
\text { [km] }\end{array}$ & $\begin{array}{c}\text { Maximum } \\
\text { distance } \\
\text { [km] }\end{array}$ \\
\hline $\mathbf{6 0}$ & 20 & $\begin{array}{r}1,7,10,13,16,17,19,24,25,29,33, \\
42,48,52,57,58,63,65,68,70\end{array}$ & 14.96 & 49 \\
\hline $\mathbf{9 0}$ & 8 & $1,13,20,29,45,52,62,68$ & 32.10 & 85 \\
\hline $\mathbf{1 2 0}$ & 4 & $7,29,44,57$ & 51.28 & 112 \\
\hline
\end{tabular}

Source: Authors 
Based on the covering distance curve, we estimated the number of facilities. The estimation was confirmed by the application of the neighborhood search algorithm. We obtained the optimal number and location of facilities considering all chosen variants of covering distance. We also found the average and the maximum distance from the facility to the nodes that this certain facility covers (Table 1).

Illustration shows the covering regions for the result of allocation of four facilities (Figure 4). Number of demands covered is not uniform. Most demands are served by the facility located at node no. 7 (west region). It's up to $37.6 \%$ of all demands.

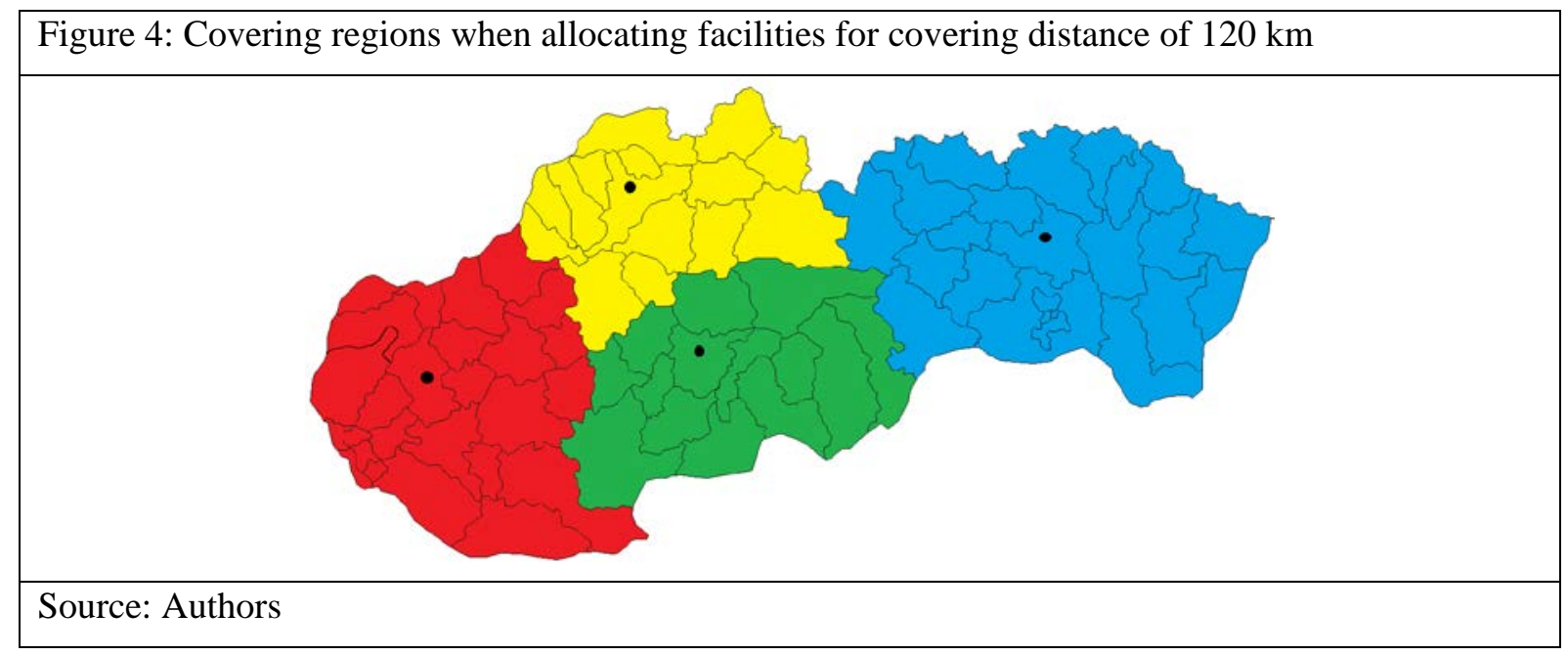

The results are not mostly based on the predetermined covering distance. Real situations demands to locate as little number of facilities as possible. The P-median allocation model can calculate the average and maximum distance from the facility to served nodes. The distance depends entirely on the number of allocated facilities. Since the available model and software require the value of covering distance to be specified, it is essential to use distance between the outermost nodes (511 km) in order to ensure that all demands are covered.

\begin{tabular}{|r|r|r|r|}
\hline \multicolumn{3}{|c|}{ Table 2: The obtained solution to the allocation problem with a minimal number of facilities } \\
\hline $\begin{array}{r}\text { Number of facilities } \\
\text { [P] }\end{array}$ & $\begin{array}{c}\text { Facility location } \\
\text { [Vertex number] }\end{array}$ & $\begin{array}{c}\text { Average distance } \\
\text { [km] }\end{array}$ & $\begin{array}{c}\text { Maximum distance } \\
\text { [km] }\end{array}$ \\
\hline 1 & 40 & 151.00 & 343 \\
\hline 2 & 12,57 & 81.80 & 176 \\
\hline 3 & $7,35,68$ & 59.40 & 143 \\
\hline \multicolumn{4}{|r|}{ Source: Authors } \\
\hline
\end{tabular}

\section{Conclusion}

Using the P-median, we were able to allocate mail sorting centers on road infrastructure while minimizing the average distance between the centers (facilities) and individual network nodes. The results can serve in understanding the issue of interconnection between creating postal networks and the use of allocation theory for their optimization. Due to limitations in the analysis of road infrastructure, the obtained solution can be considered sub-optimal. To improve the solutions, it is necessary to analyze other infrastructure parameter, e.g. road categories, time required to cover the distance, the cost of each route, etc. Long-term strategy for the development of road infrastructure and its future potential cannot be forgotten, and neither are the costs of building new centers and 
connection to utility lines. The location and construction of sorting centers are undoubtedly required in such strategic investments.

\section{Acknowledgement}

This contribution was undertaken as part of the research project KEGA 030ŽU-4/2015 Transformation of education in the field of postal technologies, networks, and services.

\section{References}

Černý, J., \& Kluvánek, P. (1991). Základy matematickej teórie dopravy [Basics of mathematical theory of transport]. Bratislava, Slovakia: Veda.

Čorejová, T., Achimský, K., Fitzová, M., \& Kajánek, B. (1995). Projektovanie sietí v pošte I. [Designing networks in postal industry I.]. Žilina, Slovakia: Edičné stredisko VŠDS.

Daskin, M. S. (2013): Network and discrete location: Models, algorithms and applications (Second ed.). Hoboken, NJ: John Wiley \& Sons.

Daskin, M. S. (2010). Service Science. Hoboken, NJ: John Wiley \& Sons.

Janáček, J. (2006). Optimalizace na dopravních sítích [Optimization on transport networks] Žilina, Slovakia: EDIS.

Madleňák, R. (2005). Algoritmy vhodné pre optimalizáciu najvy̌šej úrovne poštovej prepravnej siete [Algorithms suitable for optimization of highest level of postal transport network]. Doprava a Spoje, 1(1). Retrieved March 4, 2015, from http://fpedas.uniza.sk/dopravaaspoje/index.php

Madleňák, R., Madleňáková, L., \& Štefunko, J. (2014). The optimization variants of postal transportation network. Reliability and Statistics in Transportation and Communication, 14. Riga, Latvia: TSI. 